\title{
Madrid-72: relaciones diplomaticas y juegos olímpicos durante el Franquismo
}

Juan Antonio Simón*

\begin{abstract}
Resumen: El objetivo de este artículo es el tratar de comprender el papel que desempeñó el Ministerio de Asuntos Exteriores en la candidatura de Madrid para albergar los Juegos Olímpicos de 1972. La documentación del Archivo del Ministerio de Asuntos Exteriores (AMAE) me ha permitido analizar cómo esta institución utilizó a los embajadores y diplomáticos españoles para lograr influir en los miembros del Comité Olímpico Internacional (COI). Al mismo tiempo, el artículo muestra el enfrentamiento existente entre los miembros del gobierno español para apoyar la candidatura olímpica de Madrid.
\end{abstract}

Palabras clave: Juegos olímpicos. Franquismo. España. Deporte. Relaciones Internacionales.

\section{INTRODUCCIÓN}

A mediados de los años sesenta, la posibilidad de que España pudiera conseguir celebrar unos Juegos Olímpicos por primera vez en su historia, suponía para las autoridades franquistas una oportunidad irrenunciable dentro del contexto político existente en aquel periodo. Albergar el mayor acontecimiento deportivo internacional, permitiría al régimen dictatorial disponer de un escaparate ideal para difundir al mundo la nueva imagen de un país, que desde principios de la década se había impuesto como objetivo primordial de su política exterior, intensificar las relaciones con sus vecinos europeos. Frente a las voces que continuaban criticando el mantenimiento en plena Europa de un régimen dictatorial, la olimpiada permitiría a Franco disfrutar de una ocasión única para mostrar una "Nueva España" aparentemente más respetuosa con los derechos y libertades de sus ciudadanos y abierta a las influencias exteriores.

*Investigador Postdoctoral. Centro de Estudios Olímpicos. Universidad Autónoma de Barcelona. Barcelona, España. E-mail: jasimonsanjurjo@hotmail.com 
Pese a los múltiples estudios que durante las últimas décadas han afrontado desde distintas perspectivas la relación entre la dictadura franquista y el deporte, aún quedan muchos aspectos que por su transcendencia y repercusión están demandando un urgente y riguroso análisis historiográfico (SHAW, 1987; FERNÁNDEZ, 1990; BAHAMONDE, 2002; BIELSA, 2003; GONZÁLEZ, 2002, 2005; SANTACANA, 2006; PUJADAS, 2011). Un claro ejemplo de lo anterior, es la falta de trabajos científicos sobre la candidatura de Madrid a las olimpiadas de 1972 y el grado de implicación de las diferentes instituciones franquistas en este proyecto.

Por lo tanto, el objetivo principal de este artículo será el tratar de demostrar cómo se involucrará el Ministerio de Asuntos Exteriores de España, principalmente a través de sus representantes diplomáticos, en el sueño olímpico de Madrid; y cuáles serán los métodos que utilizará para conseguir asegurar el respaldo de los miembros del Comité Olímpico Internacional (COI).

\section{La politica deportiva durante el Franquismo}

El deporte, como todas las actividades culturales, educativas y sociales durante la dictadura franquista, estará bajo el control directo del Estado. Falange Española Tradicionalista y de las JONS (FET y de las JONS), como partido único, pasará a dirigir el deporte, teniendo desde 1941 a la Delegación Nacional de Deportes (DND) de FET de las JONS, como la principal institución deportiva del país (BIELSA, 2003).

La implementación de los órganos que dirigirán la política deportiva, coincidirá con una primera fase de autarquía, aislamiento y fuerte presión internacional desde el final de la Guerra Civil en 1939 hasta el inicio de la década de los cincuenta. Esta situación también tendrá su inmediato reflejo a nivel deportivo. La participación en competiciones internacionales se reducirá en estos años prácticamente a los enfrentamientos con países como Alemania, Italia y Portugal. Durante este periodo el objetivo de FET de las JONS 
será el tratar de movilizar a las masas bajo la bandera de la actividad física, en un contexto en el que fácilmente se pudieran reflejar los supuestos valores hispánicos masculinos como la virilidad, la impetuosidad y la furia; al mismo tiempo, que también se buscará que los mejores deportistas alcanzasen el reconocimiento mundial en los Juegos Olímpicos y cualquier en tipo de competición internacional.

El 4 de noviembre de 1950 la Asamblea General de la ONU votará la autorización para el regreso de los embajadores a Madrid. El proceso de integración será gradual, destacando como principales puntos de inflexión los acuerdos alcanzados con los Estados Unidos el 23 de septiembre de 1953 y la firma previa del Concordato con la Santa Sede en agosto del mismo año (MATEOS; SOTO, 1997; LLEONART, 1991; POWASKI, 2000; GADDIS, 2008.). Ambos acontecimientos representarán los dos principales símbolos de un cambio radical en la estrategia política, tanto a nivel nacional como internacional. En esta segunda fase en la que se consolidará la dictadura, España tratará de reforzar su imagen de "centinela de Occidente" en pleno proceso de Guerra Fría, normalizando sus relaciones deportivas con los países occidentales, pero al mismo tiempo, prohibiendo taxativamente cualquier contacto entre clubes y selecciones nacionales con los países de la órbita comunista y sobre todo con la Unión Soviética. Un ejemplo de esta actitud será el boicot que realice España junto con Holanda y Suiza a los Juegos Olímpicos de Melbourne en 1956, ante la negativa al veto a la Unión Soviética por la ocupación de Budapest un mes antes del inicio de las olimpiadas. Otra muestra de esta tendencia, será la oposición del gobierno de Franco a permitir el encuentro de fútbol entre las selecciones española y soviética en la primera edición de la Copa de Europa de Naciones en 1960. Por último, el equipo de baloncesto del Real Madrid también sufrirá este tipo de prohibiciones, cuando desde el nacimiento de la Copa de Europa en 1957 coincida en varias ocasiones con equipos soviéticos, viéndose obligado a retirarse de la competición por no poder competir con estos clubes compuestos, "[...] de un personal 
más o menos incontrolable y susceptible de producir enojosos incidentes que pueden acabar de una manera desagradable al ser representantes de países del telón de acero" (Archivo Ministerio de Asuntos Exteriores [AMAE], 1956, 17 jul.; SIMÓN, 2012).

Pero a partir de 1960 se identificará una evidente transformación en la utilización política del deporte, influida directamente por el cambio en la política exterior de un gobierno que estaba orientando su agenda hacia las relaciones con la Comunidad Económica Europea y la renovación de los acuerdos con los Estados Unidos, previamente al restablecimiento de las relaciones diplomáticas con los países de la Europa Oriental a finales de la década. El proyecto deportivo de FET de las JONS comenzará a mostrar sus importantes deficiencias, debido principalmente a la ausencia de una voluntad política y económica real, que permitiera lograr una verdadera socialización de la actividad física en España. Como contraposición a esta incuestionable carencia, se fomentará la explotación del deporte-espectáculo en general y concretamente del fútbol, junto con la utilización de esta actividad como medio propagandístico y como elemento que también permitiría favorecer las relaciones internacionales. Dentro de este último concepto, se insertará el proyecto de la candidatura de Madrid para acoger la olimpiada de 1972 (SANTACANA, 2011).

\section{EL MINISTERIO DE ASUNTOS EXTERIORES AL SERVICIO DE LA CANDIDA- TURA OLÍMPICA}

Barcelona y Madrid presentarán separadamente a finales de 1965 sus propias candidaturas al Comité Olímpico Español (COE). El 26 de diciembre de ese mismo año se hará pública la elección de la ciudad madrileña como candidata española a la celebración de la vigésima edición de los Juegos Olímpicos. JoséAntonio Elola-Olaso, presidente del COE y de la DND, decidirá el día de nochebuena, aprovechando la ausencia por vacaciones de los miembros catalanes del COE, conceder a Madrid la representación olímpica. Barcelona se tendrá que conformar con ser únicamente subsede de las pruebas de vela (HERRERA, 2012; MELÉNDEZ, 1965). 
Hasta la celebración de la Asamblea General del COI en abril de 1966, no se conocerá si Madrid lograría imponerse a Múnich, Detroit y Montreal. Mientras tanto, Ramón Sedó, como Director General del Ministerio de Asuntos Exteriores, enviará a 38 embajadores el 25 de marzo de 1966 una circular reservada ordenándoles que iniciasen los contactos con los delegados del COI en sus respectivos países, poniendo en funcionamiento una clara maniobra con la que se buscaba asegurar el éxito de Madrid en la futura votación:

Considerando el gran interés que para España tendría la aceptación de su candidatura frente a las de Alemania Occidental, Canadá y EE.UU, convendría que V.E., con el mayor tacto y discreción pues el reglamento olímpico prohíbe todo tipo de gestiones oficiales, se pusiera en contacto privadamente con: [nombre miembro del COI] Miembro del Comité Olímpico Internacional en ese país y tratase de conseguir su apoyo a la candidatura española. (AMAE, 1966)

El COI prohibía taxativamente estas actividades, pero Sedó sabía que gran parte del éxito de la candidatura española dependería de la presión e influencia diplomática que se ejerciera. Siguiendo dichas órdenes, el embajador español en Viena, Antonio de Luna, informaba al Ministerio el 4 de abril sobre las conversaciones que había mantenido con Manfred Mautner Ritter von Markhof, miembro austriaco del COI que mostraba una "gran simpatía por España". Ritter le había declarado "[...] paladinamente que no veía mal las perspectivas españoles [sic.] y desde luego que le encantaría que la Olimpiada se celebrara en Madrid" (AMAE, 1966).

Menos suerte tendría en Lima Ángel Sanz Briz, quien comunicará que Eduardo Dibós había salido del país con la intención de realizar un largo viaje por Europa de tres meses que también le llevaría a España, aconsejando que la gestión con el miembro del COI fuera realizada "durante la permanencia en España del señor Dibós" (AMAE, 1966, 5 abril). Luis García de Llera, embajador español en Tokyo, también iniciará "[...] las gestiones encomendadas 
con la extrema discreción que el caso requiere, por la circunstancia que en aquella se señala" con Ryotaro Azuma y Takaishi, los dos miembros japoneses del COI. Se asegurara de transmitir al primero de ellos, "[...] el enorme interés de España de que la olimpiada de 1972 se celebre en nuestro país", aunque no mencionará nada respecto a su posible voto (AMAE, 1966, 15 abr.).

Pero la baza más importante para el éxito de España se centrará en el supuesto respaldo de los países sudamericanos. El 13 de abril el embajador en México, Gabriel Martínez de Mata, contactará con Madrid mencionando que el Secretario de la Embajada, Enrique Mahou, se había entrevistado con el ingeniero Marte R. Gómez. En dicha conversación, se le había asegurado: "[...] el apoyo absoluto de Méjico para la solicitud española añadiendo [...] que votaría a favor de España tanto por convicción como por obligación moral, ya que España había votado siempre a favor de Méjico en las tres ocasiones en que este país ha presentado su candidatura olímpica. Al mismo tiempo, se le transmitirá al embajador la seguridad de que se iba a realizar "[...] un voto bloque de los países iberoamericanos en favor de la petición española", ofreciéndose a favorecer dicha estrategia en la futura reunión de Roma (AMAE, 1966).

El ingeniero Marte R. Gómez también alertará a España sobre las acciones que habían emprendido otras ciudades candidatas. Un "[...] representante canadiense" trató de entrevistarse con él, pero no lo "había recibido personalmente para evitarse la necesidad de una negativa concreta". Igualmente, apostaba por Madrid y Múnich como "los únicos candidatos serios", añadiendo que esta última candidatura "podría ser muy peligrosa para España". Alemania Federal se había portado de forma "muy generosa con Méjico con vistas a la Olimpiada de 1968 que organizará este país y probablemente con la intención de obligar moralmente al Comité Olímpico Mejicano a considerar de manera favorable la candidatura de Múnich". Del mismo modo, había ofrecido ocho becas a jinetes mejicanos, junto con abundante "ayuda técnica y el envío de profesores y entrenadores de atletismo y educación física para el equipo mejicano que actuará en los próximos Juegos Olímpicos". 
Marte R. Gómez confirmaba que Madrid "contaba con el apoyo de los países iberoamericanos", y que existían muchas posibilidades de que "los países del telón de acero no quieran dar su voto a Alemania Occidental, a causa de la postura que ésta adopta frente a la República Democrática Alemana y a los continúos [sic.] problemas que se presentan, también en el terreno deportivo, entre las dos Alemanias". La clave del éxito de Madrid residiría "en la habilidad con que los representantes españoles sepan maniobrar ante los países del bloque oriental" (AMAE, 1966, 13 abr.).

Siguiendo con la estrategia de asegurarse el respaldo de los países del centro y sur del continente americano, el encargado de negocios de España en La Habana, Ramón Oyarzum, escribe el 26 de abril que el "[...] comité olímpico cubano me comunica apoyará candidatura Madrid juegos 1972" (AMAE, 1966). Desde Bogotá el conde Montefuerte aseguraba que Julio Gerlein Comelin, representante colombiano del COI, también "ha prometido todo su apoyo"; al igual que Agustín Sosa, el delegado panameño que confirmó "el voto de Panamá para nuestra candidatura", aconsejando el diplomático español que "con la discreción del caso, ofrecerle a Sosa el billete de avión ida y vuelta a Roma. Espero que me respaldes en esta actitud y que la saques a nuestro común amigo Elola, el billete por Iberia que ofrecí" (AMAE, 1966, 15 abr.).

Tanto el COE como la DND también confiaban en conseguir el apoyo de los países del norte de África. Salvador García de Pruneda y Ledesma, contactará con el tunecino Mohamed M'Zali, quien confirmará su respaldo al proyecto olímpico español. M'Zali mostró una contrastada "simpatía hacía nuestro país", a la que se unían aspectos como "la proximidad geográfica y similitud de clima entre España y Túnez que favorecerán la actuación de los atletas de la Olimpíada en España" (AMAE, 1966, 25 abr.). El ingeniero egipcio y representante del COI, Ahmed El Demerdash Touny, también mostrará en sus conversaciones con los diplomáticos españoles un "especial cariño y admiración por España que ha visitado en varias ocasiones", asegurando que se podría "contar con máximo apoyo". 
Igualmente, el embajador en Rabat confirmaba el respaldo del delegado olímpico marroquí a la candidatura española (AMAE, 1966, 6 abr.).

Mayores dificultades encontrará el Ministerio de Asuntos Exteriores en otros países como India y Pakistán, con los que todavía existían muy pocas relaciones diplomáticas. El embajador de España en Karachi, Pedro Seoane y Diana, mencionaba que había "[...] remitido al Sr. Syed Wajid Alí propaganda turística y folletos de diversa índole que se encuentran al alcance de esta Embajada", aunque no esconderá las dificultades que existían dada "la vinculación de sus negocios con los Estados Unidos y el deslumbramiento que dicho país ejerce en estas Naciones" (AMAE, 1966, 11 abr.). El encargado de negocios en Nueva Delhi, Guillermo Nadal, también dirige un despacho al ministro de Asuntos Exteriores informándole que se había reunido con el Raja Bhalindra Singh, y que el presidente del Comité Olímpico de la India no estaba interesado en acudir a la Asamblea de Roma, pero que "apoyaría nuestros deseos con el Sr. G.D. Sondhi, miembro de dicho comité, que asistiría a dicha reunión en representación de la India" (AMAE, 1966, 25 abr.).

En cuanto a los miembros europeos del COI, la documentación a la que he tenido acceso me ha permitido descubrir que mediante una "discreta gestión", el embajador en Helsinki, Manuel Viturro, trató de conseguir el apoyo de los dos miembros del COI finlandeses: Johan Wilhelm Rangell y Erik von Frenckell. Viturro organizó un almuerzo en el que le informaron de "las favorables consecuencias" que tendrían para la candidatura de Madrid la decisión de la Unión Soviética de vetar "la celebración de los Juegos en Alemania Occidental". Dicha decisión "aumentaba, a su juicio, las posibilidades de la candidatura española 'en un 100/100", dado que al haberse celebrado los últimos Juegos Olímpicos en Tokio y estar concedida a México la próxima olimpiada, "era criterio general y estaba tácitamente admitido por adelantado que la de 1972 habría de celebrarse en Europa" (AMAE, 1966, 18 abr.). 
Los delegados mostraron al embajador sus dudas ante la carencia de relaciones diplomáticas que tenía el gobierno español con los países del Este, a lo que el diplomático les recordará "la final de las Copas Europeas de selecciones nacionales de football y la de baloncesto", que se habían celebrado previamente en Madrid entre España y Unión Soviética, y "que en ambas se había evidenciado un ambiente de perfecta cordialidad deportiva, en presencia incluso del Jefe del Estado que asistió al Estadio Bernabeu donde ondeaba la bandera soviética y sonaron los compases de la Internacional en honor del equipo visitante" (AMAE, 1966, 18 abr.).

$\mathrm{Al}$ igual que los representantes finlandeses, los dos miembros del COI suecos también transmitirán, según los despachos diplomáticos, una gran simpatía hacia la candidatura española. Inmediatamente después de recibir la comunicación del Ministerio, el embajador en Estocolmo, José Felipe de Alcover, se reunirá con el general Gustaf Dyrssen, "quien se mostró decidido partidario de que se celebren en Europa", y al que tratará de inclinarle hacia su "simpatía y preferencia por la solicitud Española", pese a que reconocerá que el representante de Alemania Federal había estado en Estocolmo para hacer propaganda "particular" a favor de Múnich. El 20 de abril Alcover invitará a los delegados a almorzar en la embajada antes de su viaje a Roma, y el general Dyrssen volverá a reiterarle que Madrid tenía muchas posibilidades debido a la "oposición de Rusia a la candidatura de Munich", mientras que Gunnar Ericsson también se mostrará "bien dispuesto para candidatura de Madrid" (AMAE, 1966, 21 abr.).

El cónsul general en Ginebra, Manuel Oños de Plandolit, no tendrá el mismo éxito en sus negociaciones, reconociendo "que no ha sido posible realizar cualquier gestión sobre el asunto". Mayor fortuna tendrá en La Haya José Manuel Aniel-Quiroga, quien contactará con el delegado holandés Jonkheer Herman, quien le reprochará al embajador que la elección de Madrid "implicaría que dos juegos sucesivos tendrían lugar en países de habla española", 
que España "no ha hecho mucha propaganda y ha empezado tarde", o que en la capital "no hay agua para los deportes náuticos" (AMAE, 1966, 20 abr.).

\section{4 ¿MadRID SE RETIRA? LOS PROBLEMAS dE FINANCIACIÓN DE LA CANDIDATURA ESPAÑOLA}

El 17 de abril de 1966, pocos días antes de dar inicio la esperada asamblea del COI, la prensa publicaba que dentro del gobierno la candidatura olímpica no había encontrado el respaldo unánime de todos los ministros, dado "[...] lo muy elevado del presupuesto que tal organización lleva consigo y, en consecuencia, los cuantiosos gastos que supondría para nuestro país" (PINA, 1966, p. 2). Inexplicablemente, no se desmentirá dicha noticia hasta el 22 de abril, cuatro días antes de la votación final, provocando que las dudas sobre la seguridad del proyecto español crecieran a través de los medios de comunicación internacionales. Finalmente, se hará pública una nota en la que se admitía la reconsideración del estudio económico previo y la decisión de mantener la candidatura española.

En sus memorias, Manuel Fraga, ministro de Información y Turismo en aquel momento, recuerda que en el Consejo de Ministros del 25 de marzo se produjo un "amplio debate sobre la propuesta de presentar a España como candidato para la próxima Olimpíada", y que dicho proyecto encontró una "fuerte resistencia de los ministros económicos, que pensaban en el elevado gasto público; otros argumentábamos en la conveniencia de dejar a Madrid, con este motivo, organizado y ordenado para un siglo". En las sucesivas reuniones volverá a discutirse este tema, llegando a reconocer Fraga que "naufraga definitivamente el tema de la Olimpiada", o que la respuesta era un "nuevo no a la Olimpiada". Las dudas se mantendrán hasta el 21 de abril, cuando "[...] los ministros económicos aceptan que nos ofrezcamos para la Olimpiada de 1972" (FRAGA, 1980, p.164, 167). 
El problema fundamental residía en la viabilidad económica del proyecto. En los diferentes informes que realizará la Comisión Interministerial creada por orden del Consejo de Ministros se tendrán que reducir reiteradamente los costes. A finales de marzo de $1966 \mathrm{el}$ montante inicial se situaba en 29.335 millones de pesetas, pero la posterior negativa de los ministros obligará a tener que volver a realizar una rápida revisión disminuyendo el total de las inversiones a 20.827 millones de pesetas. Pese a todo, parecía que únicamente el Secretario General del Movimiento, José Solís Ruiz, el ministro de Asuntos Exteriores, Fernando María Castiella y el propio Manuel Fraga, apostaban decididamente por la olimpiada (AMAE, 1966, 13 abr. / 31 marzo).

Las vacilaciones de las autoridades franquistas dificultarán el trabajo de los diplomáticos españoles. Desde Dublín, Juan José Pradera se interesará si las últimas noticias sobre la retirada de Madrid eran reales, rogándole "a V.E. me comunique si, en caso de ser ciertas dichas noticias, debo suspender la gestión iniciada", y "saber con certeza qué actitud debo adoptar en definitiva respecto a la gestión encomendada" (AMAE, 1966, 22 abr.). El comportamiento del gobierno español también provocará la perplejidad en los delegados finlandeses, por "haber leído en algunos órganos de la prensa extranjera (concretamente sueca) la opinión de que, en la propia España se habían expresado divergencias sobre si nuestro país estaba en condiciones de afrontar los cuantiosos gastos que habitualmente implica la organización de una Olimpiada" (AMAE, 1966, 18 abr.).

Las dudas que generaba la sede española serán utilizadas inmediatamente por sus competidores. Emilio Pan de Soraluce desde Panamá comunica el 15 de abril que "un miembro alemán del Comité" les había advertido de la retirada de la candidatura, "por no estar en disposición de hacer frente a los cuantiosos gastos que la celebración en Madrid de los juegos olímpicos de 1972 supondrían". Por dicho motivo, aconsejaba la conveniencia de poner "una circular telegráfica a nuestras Embajadas desmintiendo esta especie" (AMAE, 1966). 


\section{LA VICTORIA DE MÚNICH Y LAS RESPONSABILIDADES DIPLOMÁTICAS ESPAÑOLAS}

A su llegada a Roma a finales de abril, José Antonio ElolaOlaso tratará de despejar todas las dudas surgidas durante los últimos días, declarando a la prensa que la "candidatura nunca ha estado retirada", y que la realidad era que únicamente se habían "estado estudiando seriamente, durante varios meses, todas las posibilidades que dieran absoluta garantía de que la organización de las Olimpíadas en España fuesen lo más perfectas posible" (ESPAÑA, 1966, p. 42). La imagen de normalidad que pretendía transmitir la DND, contrastaba con el desinterés del alcalde de Madrid, Arias Navarro, quien ni siquiera viajará a Roma para respaldar la candidatura. ElolaOlaso será el encargado de subrayar "la garantía absoluta del apoyo de la ciudad, del Gobierno y del pueblo español" (GILERA, 1966, p. 88).

De los 72 miembros con derecho a voto que tenía el COI, sólo 61 acudieron a la capital italiana. En la primera votación los resultados fueron los siguientes: Múnich (21), Madrid (16), Montreal (16), Detroit (6), a los que se añadirá un voto en blanco y otro no valido. Al no alcanzarse la mayoría, se realizará una segunda vuelta en la que se impondrá finalmente Múnich (31), seguida de Madrid (15), Montreal (14) y un único voto en blanco.

El embajador en Roma, Alfredo Sánchez Bella, incidía días después en la importancia que había tenido la ausencia de los delegados de Portugal, Argentina, Panamá y Cuba, aunque el factor clave había "sido la inseguridad creada en torno a la presentación de la candidatura española", provocando que "muchos delegados la dieron por cierta y comprometieron su voto a favor de Munich" (AMAE, 1966, 27 abr.). Ese mismo día Ramón Sedó recibirá un informe, probablemente realizado por la DND, en el que se destacaba que salvo Rumanía los países del este habían apoyado a Montreal. Según dicho documento, Avery Brundage y el Barón de Guell habrían votado a favor de la candidatura española, junto con los dos miembros 
italianos, Colombia, Venezuela, Filipinas, Líbano, Rumanía, Chile, Perú, Túnez, Egipto, los dos delegados de México y el francés Pietri. El voto en blanco parecía pertenecer "a un país africano" (AMAE, 1966).

Cuatro días después de conocerse el resultado, Ramón Sedó escribirá al cónsul general de España en Berlín oriental, Antonio Espinosa, rogándole que le diera cuenta "de la reacción que en los círculos políticos e informativos de la llamada República Democrática Alemana ha suscitado la concesión a Munich de los Juegos Olímpicos Internacionales para 1972", y cuál había sido "la postura política general que dicha zona soviética de ocupación adoptaría al respecto" (AMAE, 1966, 30 abr.). Espinosa contestará resaltando que había sido muy escasa la reacción en la Alemania Democrática, aunque destacaba que varias publicaciones afirmaban que el miembro del COI de la República Federal Alemana, Willi Daume, había votado a favor del ingreso en esta institución del representante de Alemania Oriental, Heinz Scgöbel. Según las informaciones recogidas por Espinosa, se trataba "tan solo de una especulación, ya que la votación en el seno del Comité Olímpico fue secreta", pero dicho comportamiento podría ser verosímil como parte de "un compromiso general como contrapartida a la no-oposición del bloque soviético a la celebración de la Olimpiada en Munich" (AMAE, 1966, 12 mayo).

Parecía que finalmente los países del entorno comunista no habían boicoteado a Múnich. Sedó pedirá a José Felipe de Alcover, que si "buenamente a través de tus contactos y amistades puedes conocer lo que ha pasado en Roma", dado que la DND tampoco tenía "datos fidedignos y anda bastante a oscuras en este asunto", y de esta forma podrían "conocer un poco por donde andamos". Al Director General del Ministerio de Asuntos Exteriores le "resultaba extraña la victoria espectacular de Alemania cuando tenía tantos enemigos sobre todo los del Este" (AMAE, 1966, 27 mayo). Sin embargo, será Antonio de Luna desde Viena quien mencione la existencia de posibles "acuerdos" previos, recogidos por el periódico austriaco Die Presse, que había publicado que Múnich se había 
impuesto a Madrid "gracias al apoyo que consiguió en un descarado 'do ut des' con el grupo de países socialistas exceptuando Polonia" (AMAE, 1966, 28 abr.).

A continuación, Ramón Sedó tratará de descubrir cuál había sido la postura concreta de cada uno de los miembros del COI en la asamblea, y si había estado influenciada políticamente. El 14 de mayo contactará con los embajadores de Santiago de Chile, Manila, Dakar, Montevideo, Beirut, Teherán y Ankara, solicitándoles que "a título de simple información", descubrieran "la postura de los diferentes delegados durante esta reunión", para poder conocer y "esclarecer ciertas zonas oscuras con objeto de poder percibir el matíz [sic] político de las acciones de cada cual" (AMAE, 1966). Desde Santiago de Chile, Miguel María de Lojendio, contestará a Sedó explicando que el delegado de este país había votado "por Alemania Occidental", pero especificaba que esta decisión había sido tomada "una vez que España decidió retirar su candidatura. Según parece, Chile hubiera votado por España" (AMAE, 1966, 10 jun.).

Beirut también "apoyó con gusto la proposición de España para celebrar en Madrid las Olimpiadas" (AMAE, 1966, 17 mayo); mientras que desde Teherán, José Rives sólo podrá asegurar que la decisión tomada "debe haber carecido de todo matiz político pues si hay un país que el Irán considera con curiosidad y simpatía es España" (AMAE, 1966, 28 mayo). En cambio, el embajador en Ankara confirmará que Stuat Elrer había apoyado la candidatura de Múnich por los "fallos en la organización olímpica" (AMAE, 1966, 1 jun.).

Sedó mostrará un especial empeño en descubrir cuáles habían sido los motivos que provocaron el inesperado cambio de elección, o la ausencia de algunos miembros del COI de los que se esperaba un voto favorable. El 14 de mayo se dirigirá al encargado de negocios en La Habana mediante una carta muy similar a la que se había utilizado con los otros embajadores, pero en la que se instaba específicamente a Morán Oyarzun a que investigara, siempre "de una manera discreta", las razones que habían provocado la ausencia del delegado cubano, "a pesar de que según manifestaciones se había mostrado decidido a apoyarnos" (AMAE, 1966). Un tono muy 
parecido también se utilizará en los despachos enviados a los embajadores de Helsinki, Rabat, Estocolmo, Buenos Aires y Lisboa, subrayando un interés especial por conocer los motivos reales del delegado portugués, debido a que "todo permite creer, dado el desarrollo de las votaciones, que dicha ausencia influyó de manera importante en el resultado final" (AMAE, 1966, 14 mayo).

El inesperado cambio de opinión de los representantes finlandeses en Roma sorprenderá al Ministerio. Erik von Frenckell, explicará posteriormente "que las cosas no se habían desarrollado en Roma como estaba previsto", debido a que "la Candidatura española había suscitado desde el primer momento entre numerosos miembros del comité la impresión de no reflejar un deseo unánime y decidido de nuestra parte en cuanto a la oportunidad de albergar la Olimpiada". Nuevamente, la incertidumbre generada los días previos entorno al respaldo de la candidatura de Madrid había sido determinante para el cambió de opinión de gran parte de los miembros del COI (AMAE, 1966, 20 mayo).

\section{ConCLusiones}

Esta investigación ha tratado de demostrar cómo la política exterior del régimen de Franco se pondrá al servicio de la candidatura olímpica, dentro de una clara estrategia que buscaba la utilización del deporte como una herramienta de propaganda internacional; contrastando claramente con la indolencia que mostrará el Gobierno hacia el impulso de una verdadera socialización de la práctica deportiva entre las clases populares durante este mismo periodo. El Ministerio de Asuntos Exteriores se implicará directamente a través de sus embajadores y representantes diplomáticos, para conseguir de este modo ganarse el apoyo de los diferentes miembros del COI.

Es evidente la constatación de una apuesta por el aumento del protagonismo internacional de España en el mundo del deporte, a través de su intento de organizar grandes eventos deportivos que permitieran transformar la imagen exterior del país en un nuevo contexto de relaciones internacionales. Pero al mismo tiempo, se 
aprecia una neta división sobre la política deportiva dentro del gobierno, con ministros que se opondrán radicalmente a cualquier inversión económica en este ámbito, enfrentándose a las nuevas líneas de actuación que trataba de desarrollar la propia DND y mostrando una clara falta de consenso.

En definitiva, se demuestra que el Ministerio de Asuntos Exteriores intervendrá directamente en el proceso de preparación del proyecto de la candidatura olímpica de Madrid, descubriendo en el deporte un elemento que les permitiría mejorar las relaciones internacionales y diplomáticas dentro de una estrategia global de política exterior que se había iniciado desde principio de los años sesenta (Martínez, 1999). 


\begin{abstract}
Madrid-72: relações diplomáticas e jogos olímpicos durante o Franquismo

Resumo: O objetivo do presente artigo é tentar compreender o papel desempenhado pelo Ministério dos Negócios Estrangeiros na candidatura de Madrid para acolher os Jogos Olímpicos de 1972. A documentação do Arquivo do Ministério de Relações Exteriores (AMAE) me permitiu analisar como esta instituição utilizou os embaixadores e diplomatas espanhóis para influenciar os membros do Comitê Olímpico Internacional (COI). Ao mesmo tempo, o artigo mostra a confrontação entre os membros do governo espanhol para dar suporte à candidatura olímpica de Madrid.

Palavras chave: Jogos Olímpicos. Franquismo. Espanha. Esporte. Relações Internacionais.
\end{abstract}

\section{Madrid-72: diplomatic relacionships and} olympic games during Francoism

Abstract: The aim of this paper is to understand the role of the Ministry of Spanish Foreign Affairs in the Madrid bid for hosted the 1972 Summer Olympics. The documentation of the Archive of the Ministry of Spanish Foreign Affairs (AMAE) has allowed me to analyze how this institution used the Spanish ambassadors and diplomats to achieve influence the members of the International Olympic Committee. At the same time, the paper shows the confrontation within the members of the Spanish Government to support the Olympic bid of Madrid.

Keywords: Olympic Games. Francoism. Spain. Sport, International Relations.

\section{REFERENCIAS}

ARCHIVO MINISTERIO DE ASUNTOS EXTERIORES. Carta del Jefe Nacional del Servicio Exterior de FET y JONS a la dirección General de Relaciones Culturales. R4251 EX33, 17 jul. 1956.

ARCHIVO MINISTERIO DE ASUNTOS EXTERIORES. Despacho Alfredo Sánchez Bella. R8410 EXP24, 27 abr. 1966.

ARCHIVO MINISTERIO DE ASUNTOS EXTERIORES. Despacho Ángel Sanz Briz. R8410 EXP24, 5 abr. 1966.

ARCHIVO MINISTERIO DE ASUNTOS EXTERIORES. Despacho Antonio Espinosa. R8410 EXP24, 12 mayo 1966. 
ARCHIVO MINISTERIO DE ASUNTOS EXTERIORES. Despacho Antonio Luna. R8410 EXP24, 4 abr. 1966.

ARCHIVO MINISTERIO DE ASUNTOS EXTERIORES. Despacho Antonio Luna. R8410 EXP24, 28 abr. 1966.

ARCHIVO MINISTERIO DE ASUNTOS EXTERIORES. Despacho Emilio Pan de Soraluce. R8410 EXP24, 15 abr. 1966.

ARCHIVO MINISTERIO DE ASUNTOS EXTERIORES. Despacho Gabriel Martínez de Mata. R8410 EXP24, 13 abr. 1966.

ARCHIVO MINISTERIO DE ASUNTOS EXTERIORES. Despacho José Felipe de Alcover. R8410 EXP24, 21 abr. 1966.

ARCHIVO MINISTERIO DEASUNTOS EXTERIORES. Despacho José Manuel AnielQuiroga. R8410 EXP24, 20 abr. 1966.

ARCHIVO MINISTERIO DE ASUNTOS EXTERIORES. Despacho José Rives. R8612 EXP12, 28 mayo 1966.

ARCHIVO MINISTERIO DE ASUNTOS EXTERIORES. Despacho Juan José Pradera. R8410 EXP24, 22 abr. 1966.

ARCHIVO MINISTERIO DE ASUNTOS EXTERIORES. Despacho Luis García de Llera. R8410 EXP24, 15 abr. 1966.

ARCHIVO MINISTERIO DE ASUNTOS EXTERIORES. Despacho Manuel Valdés Larrañaga. R8410 EXP24, 17 mayo, 1966.

ARCHIVO MINISTERIO DE ASUNTOS EXTERIORES. Despacho Manuel Viturro. R8410 EXP24, 18 abr. 1966.

ARCHIVO MINISTERIO DE ASUNTOS EXTERIORES. Despacho Manuel Viturro. R8410 EXP24, 20 mayo 1966.

ARCHIVO MINISTERIO DE ASUNTOS EXTERIORES. Despacho Miguel de Lojendio. R8612 EXP12, 10 jun. 1966.

ARCHIVO MINISTERIO DE ASUNTOS EXTERIORES. Despacho Pedro Seoane. R8410 EXP24, 11 abr. 1966.

ARCHIVO MINISTERIO DE ASUNTOS EXTERIORES. Despacho encargado de negocios en El Cairo. R8410 EXP24, 6 abr. 1966.

ARCHIVO MINISTERIO DE ASUNTOS EXTERIORES. Despacho Guillermo Nadal. R8410 EXP24, 25 abr. 1966.

ARCHIVO MINISTERIO DE ASUNTOS EXTERIORES. Despacho Ramón Oyarzum. R8410 EXP24, 26 abr. 1966. 
ARCHIVO MINISTERIO DE ASUNTOS EXTERIORES. Despacho Ramón Sedó. R8410 EXP24, 25 marzo 1966.

ARCHIVO MINISTERIO DE ASUNTOS EXTERIORES. Despacho de Ramón Sedó para Antonio Espinosa. R8410 EXP24, 30 abr. 1966.

ARCHIVO MINISTERIO DE ASUNTOS EXTERIORES. Despacho de Ramón Sedó para el embajador en Lisboa. R8410 EXP24, 14 mayo 1966.

ARCHIVO MINISTERIO DE ASUNTOS EXTERIORES. Despacho de Ramón Sedó para embajadores. R8410 EXP24, 14 mayo 1966.

ARCHIVO MINISTERIO DE ASUNTOS EXTERIORES. Despacho de Ramón Sedó para José Felipe de Alcover. R8410 EXP24, 27 mayo 1966.

ARCHIVO MINISTERIO DE ASUNTOS EXTERIORES. Despacho de Ramón Sedó para Morán Oyarzun. R8410 EXP24, 14 mayo 1966.

ARCHIVO MINISTERIO DE ASUNTOS EXTERIORES. Despacho Salvador García de Pruneda. R8410 EXP24, 25 abr. 1966.

ARCHIVO MINISTERIO DE ASUNTOS EXTERIORES. Despacho Stuat Erler. R8612 EXP12, 1 junio 1966.

ARCHIVO MINISTERIO DE ASUNTOS EXTERIORES. Informe Ramón Sedó. R8410 EXP24, 27 abr. 1966.

ARCHIVO MINISTERIO DE ASUNTOS EXTERIORES. Informe Comisión Interministerial. R8612 EXP12, 13 abr. 1966.

ARCHIVO MINISTERIO DE ASUNTOS EXTERIORES. Informe Comisión Interministerial. R8612 EXP12, 31 marzo 1966.

BAHAMONDE, A. El Real Madrid en la historia de España. Madrid: Taurus, 2002.

BIELSA, R. La Delegación Nacional de Deportes 1943-1975. Tesis (Doctorado), Universidad de Extremadura, 2003.

ESPAÑA mantiene su candidatura para la organización de los Juegos de 1972. La Vanguardia, Barcelona, p. 42, 24 abr. 1966.

FERNÁNDEZ, C. El fútbol durante la guerra civil y el franquismo. Madrid: San Martín, 1990.

FRAGA, M. Memoria breve de una vida pública. Barcelona: Planeta, 1980.

GADDIS, J. L. La Guerra Fría. Barcelona: RBA Editores, 2008.

GILERA. Causa excelente impresión el discurso del presidente del Comité Olímpico Español. ABC, Madrid, p.88, 26 abr. 1966. 
GONZÁLEZ, T. (Ed.). Sport y autoritarismos: la utilización del deporte por el comunismo y el fascismo. Madrid: Alianza Editorial, 2002.

GONZÁLEZ, T. Monje y soldado. La imagen masculina durante el Franquismo. Revista Internacional de Ciencias del Deporte (RICYDE), Madrid, n. 1-I, p.6483, oct. 2005.

HERRERA, A. Barcelona, fiebre olímpica. Historia y vida, especial, Madrid, n. 9, p. 58-67, 2012.

LLEONART, A. J. España y ONU. Estudios introductivos y Corpus documental. Madrid: CSIC,1991. v. 4 (1950).

MARTÍNEZ, J. A. (Coord.). Historia de España siglo XX, 1939-1996. Madrid: Cátedra, 1999.

MATEOS, A.; SOTO, A. El final del franquismo, 1959-1975. Madrid: Historia 16Temas de Hoy, 1997.

PINA, N. Se renuncia a presentar la candidatura de Madrid y Barcelona para los Juegos Olímpicos de 1972. El Mundo Deportivo, Barcelona, p.2, 17 abr. 1966.

POWASKI, R. E. La Guerra Fría: Estados Unidos y la Unión Soviética, 1917-1991. Barcelona: Crítica, 2000.

PUJADAS, X. (Coord.). Atletas y ciudadanos: historia social del deporte en España 1870-2010. Madrid: Alianza Editorial, 2011.

SANTACANA, C. El Barça y el franquismo: Crónica de unos años decisivos para Cataluña, 1968-1978. Barcelona: Apóstrofe, 2006.

SANTACANA, C. Espejo de un régimen. Transformación de las estructuras deportivas y su uso político y propagandístico. In: PUJADAS, X. (Coord.). Atletas y ciudadanos: Historia social del deporte en España, 1870-2010. Madrid: Alianza, 2011.

SHAW, D. Fútbol y franquismo. Madrid: Alianza Editorial, 1987.

Juan Antonio Simón

Investigador Postdoctoral

Centro de Estudios Olímpicos. Universidad Autónoma de Barcelona

Universidad Autónoma de Barcelona.

Campus de Bellaterra, Edificio N, 08193

Barcelona (España)

Recebido em: 09-11-2012

Aprovado em: 10-12-2012 